\title{
Aggregation Pheromone of the Guam Strain of Coconut Rhinoceros Beetle, Oryctes Rhinoceros, and Revision of Stereochemistry
}

David R Hall ( $\nabla$ d.r.hall@gre.ac.uk)

University of Greenwich https://orcid.org/0000-0002-7887-466X

\section{Steven J Harte}

University of Greenwich

\section{Dudley I Farman}

University of Greenwich

\section{Mark Ero}

Papua New Guinea Oil Palm Research Association (PNGOPRA), Dami Research Station

\section{Alfred Pokana}

New Britain Palm Oil Limited, Quadalcanal Plains

\section{Research Article}

Keywords: (R)-4-methyloctanoic acid, ethyl (R)-4-methyloctanoate, enzymatic resolution, electroantennogram, enantiospecific gas chromatography

Posted Date: July 14th, 2021

DOl: https://doi.org/10.21203/rs.3.rs-697767/v1

License: (c) (1) This work is licensed under a Creative Commons Attribution 4.0 International License. Read Full License 


\section{Aggregation Pheromone of the Guam Strain of Coconut Rhinoceros}

2 Beetle, Oryctes rhinoceros, and Revision of Stereochemistry

3 David R Hall ${ }^{1}$ Steven J Harte $^{1}$ Dudley I Farman ${ }^{1}$ Mark Ero $^{2,4}$ Alfred Pokana ${ }^{3}$

$4{ }^{1}$ Natural Resources Institute, University of Greenwich, Central Avenue, Chatham Maritime,

5 Kent ME4 4TB, UK

$6 \quad 2$ Papua New Guinea Oil Palm Research Association (PNGOPRA), Dami Research Station, PO

7 Box 97 Kimbe, West New Britain Province, Papua New Guinea

$8 \quad{ }^{3}$ New Britain Palm Oil Limited, Quadalcanal Plains, PO Box 2001, Honiara, Solomon Islands

$9{ }^{4}$ Current Address: Pacific Community (SPC), Land Resources Division, Private Mail Bag, Suva, $10 \quad$ Fiji

12 Author for Correspondence

13 David R Hall

14 d.r.hall@gre.ac.uk

\section{Dedication}

17 This paper is dedicated to the memory of Prof Wittko Francke, a giant among chemical

18 ecologists who gave so much to science and inspired so many of our careers. We planned to

19 publish this paper alongside a paper by Profs Francke and Akasaka reporting preference for the

$20(R)$-configuration in the methyl-branched pheromones of several other genera of beetles. Rest in

21 peace, Wittko. You will be sorely missed, but your legacy and spirit will live forever. 


\section{Declarations}

\section{Funding}

25 Work at NRI was funded in part by a contract with the Papua New Guinea Oil Palm Research

26 Association (PNGOPRA).

\section{Conflicts of interest/Competing interests}

28 None

\section{Availability of data and material}

30 Raw chromatographic and trapping data are available on request from the authors

\section{Code availability}

32 N/A

\section{Authors' contributions}

34 DRH managed the chemical and analytical work, carried out chemical synthesis and was lead 35 author writing the paper; SJH carried out chemical and analytical work; DIF carried out release

36 rate measurements and preparation of lures; ME organised collection and shipping of insects and

37 field trapping work in both Papua New Guinea and the Solomon Islands. AP organized and

38 carried out field work in the Solomon Islands. All authors contributed to writing the paper.

\section{Ethics approval}

$40 \quad$ Not required

\section{Consent to participate}

42 Not required

\section{Consent for publication}

44 All authors agreed to submission of the final manuscript 


\section{Abstract}

47 The coconut rhinoceros beetle, Oryctes rhinoceros (Linnaeus 1758) (Coleoptera: Scarabaeidae: Dynastinae) (CRB), is endemic to tropical Asia where it damages both coconut and oil palm. A new invasion by CRB occurred on Guam in 2007 and eradication attempts failed using commonly applied $O$. rhinoceros nudivirus (OrNV) isolates. This and subsequent invasive outbreaks were found to have been caused by a previously unrecognized haplotype, CRB-G, which appeared to be tolerant to OrNV. The male-produced aggregation pheromone of the endemic, susceptible strain of $O$. rhinoceros (CRB-S) was previously identified as ethyl 4methyloctanoate. There were anecdotal reports that the commercial lures containing this compound were not attractive to CRB-G and the aim of this work was to identify the pheromone of CRB-G. Initial collections of volatiles from virgin male and female CRB-G adults failed to show any male- or female-specific compounds as candidate pheromone components. Only after five months were significant quantities of ethyl 4-methyloctanoate and 4-methyloctanoic acid produced by males but not by females. No other male-specific compounds could be detected, in particular methyl 4-methyloctanoate, 4-methyl-1-octanol or 4-methyl-1-octyl acetate, compounds identified in volatiles from some other species of Oryctes. Ethyl 4-methyloctanoate elicited a strong electroantennogram response from both male and female CRB-G, but these other compounds, including 4-methyloctanoic acid, did not. The enantiomers of ethyl 4methyloctanoate and 4-methyloctanoic acid were conveniently prepared by enzymatic resolution of the commercially-available acid, and the enantiomers of the acid, but not the ester, could be separated by gas chromatography on an enantiospecific cyclodextrin phase. Using this approach,

67 both the ethyl 4-methyloctanoate and the 4-methyloctanoic acid produced by male CRB-G were 68 shown to be exclusively the $(R)$-enantiomers whereas previous reports had suggested male CRB69 S produced the $(S)$-enantiomers. However, re-examination of the ester and acid produced by 70 male CRB-S showed that these were also the $(R)$-enantiomers. In field trapping experiments, 71 both racemic and ethyl $(R)$-4-methyloctanoate were highly attractive to both male and female 72 CRB-G. The $(S)$-enantiomer and the corresponding acids were only weakly attractive. Addition 73 of racemic 4-methyloctanoic acid to ethyl 4-methyloctanoate did significantly increase 74 attractiveness, but addition of $(R)$ - or $(S)$-4-methyloctanoic acid to the corresponding ethyl esters 
75 did not. Reasons for the previous misassignment of the configuration of the components of the

76 CRB-S pheromone are discussed along with the practical implications of these results.

Key Words $(R)$-4-methyloctanoic acid ethyl $(R)$-4-methyloctanoate enzymatic resolution electroantennogram enantiospecific gas chromatography

\section{$81 \quad$ Introduction}

82 The coconut rhinoceros beetle, Oryctes rhinoceros (Linnaeus 1758) (Coleoptera: Scarabaeidae:

83 Dynastinae) (CRB), is endemic to tropical Asia where it damages both coconut and oil palm, and 84 can kill palms when adults bore into crowns to feed on sap (Bedford, 2013a, 2013b). The beetle 85 was introduced into the Pacific in 1909 via potted soil with rubber tree seedlings from Sri Lanka 86 (Catley, 1969). The pest rapidly multiplied and spread throughout the Pacific Islands. However,

87 it was brought under control by the discovery and distribution of a viral biocontrol agent, Oryctes rhinoceros nudivirus (OrNV), previously known as Rhabdiovirus oryctes and Baculovirus oryctes (Bedford, 2013b; Huger, 2005). Further spread of CRB was suppressed for 30 years

90 (Secretariat of the Pacific Community, 2015) by a strategy of sanitation and biocontrol with

91 OrNV (Jackson, 2009).

However, a new invasion by CRB occurred on Guam in 2007 (Moore et al. 2015) and

93 eradication attempts failed using commonly applied OrNV isolates that cause disease in endemic

94 susceptible $O$. rhinoceros populations (CRB-S). Subsequently, new CRB invasions have been

95 reported in Port Moresby (Papua New Guinea, 2009), O’ahu (Hawai'i, USA, 2013), and Honiara

96 (Solomon Islands, 2015). Marshall et al. (2017) reported that all of these outbreaks have been

97 caused by a previously unrecognized haplotype, CRB-G, which appeared to be tolerant to OrNV.

98 PCR analysis showed that OrNV was generally present at high incidence in established

99 populations of CRB-S, but absent from the invasive CRB-G populations (Marshall et al. 2017).

101 methyloctanoate by Hallett et al. (1995) using insects from Indonesia. The stereochemistry of the 102 material produced by the beetles was not determined, but, in field trapping tests, traps baited with 
103 the racemic or the $(S)$-enantiomer caught similar numbers of beetles and significantly more than

104 those baited with the $(R)$-enantiomer. It has thus generally been assumed that the beetles produce

105 the $(S)$-enantiomer. Hallett et al. (1995) also detected 4-methyloctanoic acid and ethyl 4-

106 methylheptanoate in volatiles from male O. rhinoceros, but could not demonstrate any effect of

107 these compounds in field trapping tests. Morin et al. (1996) also found both ethyl 4-

108 methyloctanoate and 4-methyloctanoic acid in widely different relative amounts in volatiles from

109 male $O$. rhinoceros from various geographic origins.

110 There was anecdotal evidence that CRB-G was not very responsive to the commercial

111 lures for $O$. rhinoceros based on racemic ethyl 4-methyloctanoate, and this study aimed to

112 identify components of the aggregation pheromone produced by male CRB-G and to compare

113 these with those produced by the original CRB-S strain.

\section{Methods and Materials}

\section{Insect Material}

117 Insects of the Guam strain of $O$. rhinoceros (CRB-G) were collected as pupae in plantations of

118 the Guadalcanal Plains Palm Oil Limited (GPPOL; now part of Sime Darby Group of

119 Companies) in the Solomon Islands. Marshall et al. (2017) had previously confirmed that CRB

120 from this area were of the Guam strain. Insects of the susceptible strain (CRB-S) were collected

121 from Numondo plantation in West New Britain Province, Papua New Guinea. Pupae were sent in

122 individual containers to the Natural Resources Institute (NRI), UK, by air freight.

123 At NRI, pupae were maintained in a quarantine-controlled insectary at $25{ }^{\circ} \mathrm{C}, 55 \% \mathrm{RH}$

124 and 12:12 h L:D cycle. On emergence, adults were separated by sex according to Mini and

125 Prabhu (1988): males have a larger horn and bare pygidium compared with the bushy pygidium

126 with densely packed hairs of females. Adults were maintained under the above conditions on

127 sterilized soil with banana as food. 
130 Volatiles were collected from 1-7 individuals. Most collections were made from individuals of 131 one sex, but some were made from both sexes together. These were placed in a 5-litre round132 bottomed, bolt-head flask with shredded paper and a piece of sugarcane. Some collections were 133 made with banana or tinned palm hearts as food, but these produced larger amounts of volatiles

134 than sugarcane. Air was drawn into the flask (2 1/min) through a filter containing activated 135 charcoal (20 cm x $1.5 \mathrm{~cm}$; 6-10 mesh) and out through a filter made from a Pasteur pipette (4 136 mm i.d.) containing Porapak Q (200 mg; 50-80 mesh; Supelco, Gillingham, Dorset, UK). The 137 Porapak Q was extracted with chloroform in a Soxhlet apparatus for $6 \mathrm{~h}$ and washed with 138 dichloromethane immediately before use. Collections were made for periods from $24 \mathrm{~h}-72 \mathrm{~h}$.

139 Trapped volatiles were removed with dichloromethane (Pesticide Residue Grade; $1 \mathrm{ml}$ ) and 140 stored at $4{ }^{\circ} \mathrm{C}$ before analysis.

141 To convert esters in the collections of volatiles to the corresponding acids, $0.5 \mathrm{ml}$ of a 142 collection containing approximately $50 \mu \mathrm{g}$ ethyl 4-methyloctanoate was evaporated just to 143 dryness under a gentle stream of nitrogen. Ethanol $(50 \mu \mathrm{l})$ and $2 \mathrm{~N}$ aqueous potassium hydroxide

144 solution $(50 \mu \mathrm{l})$ were added and the mixture left for $6 \mathrm{~h}$ at room temperature. Water $(0.5 \mathrm{ml})$ was 145 added and the mixture was extracted with hexane $(0.5 \mathrm{ml})$. After acidification with aqueous $4 \mathrm{~N}$ 146 sulfuric acid $(50 \mu \mathrm{l})$, the mixture was extracted with two portions of diethyl ether $(0.5 \mathrm{ml})$ and 147 the combined extracts dried with anhydrous magnesium sulfate.

\section{Analysis by Gas Chromatography}

149 Collections of volatiles were analyzed by gas chromatography (GC) with flame ionization 150 detection (FID) using HP6850 instruments (Agilent Technologies, Stockport, Cheshire, UK) 151 fitted with a fused silica column (30 $\mathrm{m}$ x $0.32 \mathrm{~mm}$ i.d. $0.25 \mu$ film thickness) coated with non152 polar HP5 (Agilent) or polar DBWax (Supelco). The oven temperature was programmed from 50 $153{ }^{\circ} \mathrm{C}$ for $2 \mathrm{~min}$ than at $10^{\circ} \mathrm{C} / \mathrm{min}$ to $250{ }^{\circ} \mathrm{C}$. Carrier gas was helium $(2.4 \mathrm{ml} / \mathrm{min})$, injection was 154 splitless $\left(220^{\circ} \mathrm{C}\right)$ and detection by FID $\left(250^{\circ} \mathrm{C}\right)$.

155 Enantiospecific gas chromatography was carried out on a CP-Chirasil-Dex CB column 156 (25 m x $0.32 \mathrm{~mm} ; 0.25 \mu \mathrm{m}$ film thickness; Varian/Agilent) with helium carrier gas ( $2.4 \mathrm{ml} / \mathrm{min})$, 
157 split injection $\left(220^{\circ} \mathrm{C} ; 20: 1\right)$ and $\operatorname{FID}\left(220^{\circ} \mathrm{C}\right)$. The oven temperature was programmed from 60 $158{ }^{\circ} \mathrm{C}$ for $2 \mathrm{~min}$ then at $5{ }^{\circ} \mathrm{C} / \mathrm{min}$ to $200{ }^{\circ} \mathrm{C}$.

159 Collections were also analyzed by GC coupled to mass spectrometry (MS) using a Varian $1603700 \mathrm{GC}$ linked directly to a Saturn 2200 ion-trap MS (Varian, now Agilent). Columns (30 m x $1610.25 \mathrm{~mm}$ i.d. $0.25 \mu$ film thickness) were coated with polar DBWax (Supelco) or non-polar VF5 162 (Varian/Agilent). The carrier gas was helium $(1 \mathrm{ml} / \mathrm{min})$ and the oven temperature was 163 programmed from $40{ }^{\circ} \mathrm{C}$ for 2 min then at $10^{\circ} \mathrm{C} / \min$ to $250{ }^{\circ} \mathrm{C}$.

164 Retention Indices for compounds were calculated relative to the retention times of $n$ 165 alkanes. Amounts present in collections were estimated by comparison of peak areas with those

166 of external standards. The response factor for 4-methyloctanoic acid was much lower than that of 167 the corresponding acid in both GC-FID and GC-MS.

168 Analysis by Gas Chromatography Coupled to Electroantennographic Recording (GC169 EAG)

170 GC-EAG Analyses were carried out on a HP6890 GC (Agilent) fitted with flame ionization 171 detector (FID) and fused silica capillary columns ( $30 \mathrm{~m} \times 0.32 \mathrm{~mm}$ i.d. $\mathrm{x} 0.25 \mu \mathrm{m}$ film thickness) 172 coated with DBWax and DB5 (Supelco). Injections onto the DBWax column were in splitless 173 mode $\left(220^{\circ} \mathrm{C}\right)$, carrier gas was helium $(2.4 \mathrm{ml} / \mathrm{min})$ and the oven temperature was programmed 174 from $50{ }^{\circ} \mathrm{C}$ for $2 \mathrm{~min}$ and then at $10{ }^{\circ} \mathrm{C} / \mathrm{min}$ or $20^{\circ} \mathrm{C} / \mathrm{min}$. to $250{ }^{\circ} \mathrm{C}$ for $3 \mathrm{~min}$. The effluents of 175 the two columns were combined with a glass push-fit Y-tube connector (Agilent) connected to a 176 second Y-tube connector with deactivated fused silica tubing (10 $\mathrm{cm} \times 0.32 \mathrm{~mm}$ i.d.). One arm of

178 FID $\left(250^{\circ} \mathrm{C}\right)$ and the other to an equal length of deactivated silica tubing passing through a 179 heated transfer line $\left(250^{\circ} \mathrm{C}\right.$; Syntech, Hilversum, The Netherlands, now Kirchzarten, Germany) 180 into a glass tube (4 $\mathrm{mm}$ i.d.) through which air passed (500 $\mathrm{ml} / \mathrm{min})$ over the EAG preparation. 181 Both the FID and EAG signals were collected and analyzed with EZChrom software (Elite v3.0; 182 Agilent Technologies).

183 EAG preparations were made with glass microelectrodes filled with saline $(0.1 \mathrm{M} \mathrm{KCl}$ 184 with $1 \%$ polyvinylpyrrolidone) attached to silver wire electrodes held by integrated electrode 185 holders, micromanipulators and amplifier (INR-2; Syntech). One antenna was removed and the 
186 base inserted into the indifferent electrode. Following the description of the antennal

187 morphology on O. rhinoceros (Renou et al., 1998), the club was opened out to reveal the

188 lamellar structure and the end of the recording electrode was placed on the surface of one of the 189 lamellae. EAG responses were amplified x10.

190 Chemicals

191 Racemic ethyl 4-methyloctanoate was prepared by refluxing commercially available 4-

192 methyloctanoic acid (SigmaAldrich, Gillingham, Dorset, UK) in ethanol with a drop of sulfuric 193 acid for $1 \mathrm{~h}$ followed by evaporation of most of the ethanol. This was repeated with a further 194 portion of ethanol, followed by aqueous work-up and fractional distillation to give the product in $19586 \%$ yield.

The enantiomers of 4-methyloctanoic acid and the corresponding ethyl ester were 197 conveniently resolved enzymatically in multigram quantities as reference standards and for field 198 testing. Heinsman et al. $(1998 ; 2001)$ reported that immobilized lipase from Candida antarctica 199 acted selectively on the $(R)$-enantiomer, so that the acid could be selectively esterified in ethanol 200 or the ethyl ester could be selectively hydrolyzed in $1 \mathrm{M}$ aqueous $\mathrm{K}_{2} \mathrm{HPO}_{4}$. Moreover, the acid 201 could be separated from the ester by extraction with aqueous base and subsequent acidification 202 without resort to chromatography.

The sequence of reactions is shown in Fig. 1 with the enantiomeric excess (ee) of the products, and detailed procedures are described in the Supplementary Material. Enantiomers of 205 ethyl 4-methyloctanoate could not be separated by GC analysis on the cyclodextrin column used 206 here, but those of the corresponding acid could, as also found by Karl et al. (1994b) (ester 12.10 207 min, $(R)$-acid $18.06 \mathrm{~min},(S)$-acid $18.14 \mathrm{~min})$. Thus the enantiomeric composition of the ester 208 products was assessed by hydrolyzing a small portion of the ester with potassium hydroxide in 209 aqueous ethanol for $6 \mathrm{~h}$ and work-up as described above for collections of volatiles. The 210 stereochemistry of the products was further confirmed by comparison with a sample of 4211 methyloctanoic acid enriched in the $(R)$-enantiomer provided by Prof Angel Guerrero (Muñoz et 212 al. 2009). 
215 of ethyl 4-methyloctanoate with lithium aluminum hydride in ether and acetylated with acetic

216 anhydride in pyridine to give 4-methyloctyl acetate. Details are given in the Supplementary

217 Material. Compounds were characterized by their ${ }^{1} \mathrm{H}-$ and ${ }^{13} \mathrm{C}-\mathrm{NMR}$ spectra, their GC retention

218 indices (Supplementary Material Table S2) and mass spectra (Supplementary Material Figs. S1, 219 S2).

(E)-Geranic acid was prepared by low temperature crystallization $\left(-80{ }^{\circ} \mathrm{C}\right)$ of commercially available geranic acid (SigmaAldrich) in petroleum spirit (b.p. $40-60{ }^{\circ} \mathrm{C}$ ) or

222 acetone. Analysis of the commercial material on a polar GC column showed the (E)- and $(Z)$ 223 isomers in 76:24 ratio. Two recrystallizations gave material > 99\% $(E)$-isomer.

\section{Pheromone Dispensers}

225 Sealed polyethylene vials (30 mm x $15 \mathrm{~mm}$ x $1.5 \mathrm{~mm}$ thick; Fisher Scientific, Loughborough, 226 Leicestershire, UK) and polyethylene sachets ( $5 \mathrm{~cm}$ x $5 \mathrm{~cm}$ x $60 \mu$ thick, $5 \mathrm{~cm} \times 5 \mathrm{~cm} \times 120 \mu$, $2272.5 \mathrm{~cm} \times 5 \mathrm{~cm} \times 250 \mu$ ) prepared by heat sealing layflat tubing (Transpack Ltd, Southampton, 228 UK) were evaluated as dispensers in laboratory and field. The test compound was impregnated 229 onto cotton dental rolls (19 $\mathrm{mm}$ x $8 \mathrm{~mm}$ and $38 \mathrm{~mm}$ x $8 \mathrm{~mm}$ in vials and sachets, respectively).

230 Standard CRB lures were blister packs (27 mm diameter) containing approximately $1 \mathrm{ml}$ ethyl 4231 methyloctanoate (P046 Sime RB Pheromone, distributed by Sime Darby Agri-Bio Sdn Bhd, 232 Selangor, Malaysia, and manufactured by ChemTica Internacional, Costa Rica).

233 Release rates were determined for dispensers maintained in a laboratory fume hood at 20$23422{ }^{\circ} \mathrm{C}$ by periodic weighing of duplicate dispensers and calculation of mean weight loss. Release 235 rates are given in Table 1 and data are shown in Supplementary Material Figs. S3-S6).

\section{Field Trapping Experiments}

\section{Traps}

238 Traps were constructed from PVC pipe (3 m long x $15 \mathrm{~cm}$ diameter) with open ends positioned 239 vertically with the lower end in a bucket on the ground to capture beetles. Beetles could enter at 240 the top end and by two windows $(20 \mathrm{~cm} \times 12 \mathrm{~cm})$ cut in opposite sides of the pipe at $40 \mathrm{~cm}$ and $24172 \mathrm{~cm}$ from the top respectively. The lure was hung inside the pipe $15 \mathrm{~cm}$ from the top end. 


\section{Trapping Experiments}

243 Two field trapping experiments were carried out in plantations of the Guadalcanal Plains Palm

244 Oil Limited (GPPOL; now part of Sime Darby Group of Companies) in the Solomon Islands.

245 Marshall et al. (2017) had previously confirmed that CRB from this area were of the Guam

246 strain. In the first experiment (8 May - 6 June 2017), catches were compared in traps baited with

247 single components, racemic, $(S)$ - and $(R)$-enantiomers of ethyl 4-methyloctanoate dispensed from

248 polyethylene vials, racemic, $(S)$ - and $(R)$-enantiomers of 4-methyloctanoic acid dispensed from a

249 standard thickness $(120 \mu)$ sachet and $(E)$-geranic acid in a thin-walled sachet $(60 \mu)$.

250 In the second experiment (20 June - 11 July 2017), catches were compared in traps baited 251 with racemic, $(S)$ - and $(R)$-enantiomers of ethyl 4-methyloctanoate dispensed from polyethylene 252 vials, combinations of racemic, $(S)$ - and $(R)$-enantiomers of ethyl 4-methyloctanoate with the 253 corresponding acid dispensed from polyethylene vials and thick (250 $\mu$ ) polyethylene sachets 254 respectively, and ethyl 4-methyloctanoate dispensed at a higher rate from a sachet. Both 255 experiments included unbaited traps and traps baited with the standard ChemTica lure as 256 negative and positive controls respectively. Details of the lures are given in Table 2.

Traps were deployed in randomized complete blocks with $50 \mathrm{~m}$ between traps in a block

258 and at least $100 \mathrm{~m}$ between blocks. There were six replicate blocks in each experiment and 259 catches were sexed, counted and discarded weekly. Total catches were transformed to $\log (x+1)$ 260 and subjected to analysis of variance, omitting treatments with zero catches. Where significant 261 differences $(P<0.05)$ were indicated, differences between means were tested for significance $(P$ $262<0.05)$ by a Least Significant Difference (LSD) test.

\section{Results}

\section{Collection and Analysis of Pheromone of Guam Strain of Oryctes rhinoceros (CRB-G)}

266 CRB-G insects were received at NRI on 4 November 2016 and either emerged in transit or soon 267 after arrival. Collections of volatiles were made at least once a week from male and female 268 beetles separately $(N=32$ collections each) through until 18 April 2017. No obvious differences 269 in volatiles collected from males and females were detected by GC-MS analyses until 12 April 
270 2017, i.e. over 5 months after emergence, when ethyl 4-methyl octanoate was detected. A 271 collection from five males for $24 \mathrm{~h}$ yielded approximately $100 \mu \mathrm{g}$ ethyl 4-methyloctanoate and

$27225 \mu \mathrm{g}$ 4-methyloctanoic acid, while neither compound could be detected in a parallel collection

273 from seven females (Fig. 2). Subsequent collections from the same males yielded amounts of the 274 ester and acid, respectively, of $200 \mu \mathrm{g}$ and $400 \mu \mathrm{g}$ from three males and $250 \mu \mathrm{g}$ and $600 \mu \mathrm{g}$ from 275 one male, both for $65 \mathrm{~h}$, followed by $20 \mu \mathrm{g}$ acid only from two individual males for $48 \mathrm{~h}$, and 276 finally $7.5 \mu \mathrm{g}$ acid from the one remaining male over $24 \mathrm{~h}$.

The only exception to the above was in early December 2016 when the (E)- and (Z)isomers of geranic acid were detected in 97:3 ratio. In collections from a single male for $60 \mathrm{~h}$ $850 \mu \mathrm{g}$ was detected, followed by $180 \mu \mathrm{g}$ during the next $24 \mathrm{~h}$. Parallel collections from a single female yielded $100 \mu \mathrm{g}$ and $20 \mu \mathrm{g}$ respectively. Subsequent collections from different insects on fresh sugarcane yielded small but detectable amounts of geranic acid.

The identifications of ethyl 4-methyloctanoate and 4-methyloctanoic acid were confirmed by identical retention times with synthetic standards in GC-FID analyses on polar, non-polar and cyclodextrin GC columns, and by identical retention times and mass spectra in GC-MS analyses on a polar GC column. Methyl 4-methyloctanoate, 4-methyl-1-octanol and the corresponding 286 acetate could not be detected.

In analyses of volatile collections containing both ethyl 4-methyloctanoate and 4methyloctanoic acid on the cyclodextrin column, the acid was exclusively the earlier eluting $(R)$ enantiomer. After hydrolysis of the ester in the samples, analysis showed only the $(R)$ enantiomer of the acid, confirming that the ester also had the (R)-configuration (Fig. 3).

\section{Analysis by Gas Chromatography Coupled to Electroantennographic Recording (GC-} 292 EAG)

293 In GC-EAG analyses of early collections of volatiles from male or female CRB-G beetles, no 294 consistent EAG responses were detected from antennae of male or female beetles $(N=6)$. antennae of both males and females to ethyl 4-methyloctanoate. A response was occasionally 
observed to the corresponding methyl ester, but no response was observed to 4-methyl-1-octanol, 298 the corresponding acetate or 4-methyloctanoic acid (Fig. 4).

EAG responses from antennae of both males and females were generally greater to ethyl

300 (R)-4-methyloctanoate than to the (S)-enantiomer (Supplementary Material Fig. S7). This was

301 not examined rigorously as available samples of both enantiomers contained small amounts of

302 the opposite enantiomer. However, in one example, mean responses ( $N=2$ delivered alternately)

303 from the antenna of a male beetle were $0.28 \mathrm{mV}$ and $0.14 \mathrm{mV}$ to the $(R)$ - and $(S)$-enantiomers

304 (10 ng), respectively, and from the antenna of a female beetle $0.32 \mathrm{mV}$ and $0.10 \mathrm{mV}$,

305 respectively.

\section{Pheromone of Susceptible Strain of Oryctes rhinoceros (CRB-S)}

307 Beetles and emerging pupae of the susceptible strain of 0 . rhinoceros (CRB-S) were received at 308 NRI on 23 February 2018. Volatiles were collected from males at 3-4 dintervals, but it was not 309 until 10 April 2018 that 4-methyloctanoic acid was detected in collections from males and ethyl 310 4-methyloctanoate was not detected until 18 April 2018 (Supplementary Fig. S8). Production of

311 both continued at declining levels until 27 April 2018 after which neither compound was 312 detected until collections were terminated on 16 May 2018. The two collections with most 313 material contained $170 \mu \mathrm{g}$ and $23 \mu \mathrm{g}$ ethyl 4-methyloctanoate, and $830 \mu \mathrm{g}$ and $109 \mu \mathrm{g} 4-$

314 methyloctanoic acid, respectively, collected over $24 \mathrm{~h}$ from two male beetles. These compounds 315 were never detected in collections from females.

316 In analyses of volatile collections on the cyclodextrin column, the 4-methyloctanoic acid 317 co-chromatographed with the $(R)$-enantiomer. After hydrolysis of the ethyl ester present, analysis 318 showed only $(R)$-4-methyloctanoic acid, confirming that the ester also had the $(R)$-configuration 319 (Supplementary Material Fig. S9).

\section{Trapping Experiments}

321 In both trapping experiments, catches of male and female $O$. rhinoceros Guam strain beetles 322 (CRB-G) were similar and analyses were carried out on the combined catch. In the first trapping 323 experiment (Fig. 5), catches of CRB-G beetles in traps baited with racemic or the $(R)$-enantiomer 324 of ethyl 4-methyloctanoate were significantly higher than those in traps baited with the $(S)$ - 
enantiomer. Catches in traps baited with the corresponding acids and $(E)$-geranic acid were low,

326 although significantly different from the zero catches in unbaited traps. Catches with the $(S)$ -

327 enantiomer of 4-methyloctanoic acid were lower than those with the $(R)$-enantiomer, although

328 not significantly so because of the low numbers caught. Catches were highest in traps baited with

329 the ChemTica lure, although not significantly higher than those baited with racemic ethyl 4-

330 methyloctanoate in a polyethylene vial, even though the release rate was almost an order of

331 magnitude greater $(9.1 \mathrm{mg} / \mathrm{d}$ and $1.0 \mathrm{mg} / \mathrm{d}$, respectively, Table 1$)$.

332 In the second experiment (Fig. 6), addition of the corresponding acid to racemic ethyl 4-

333 methyloctanoate significantly increased catches, although addition of the corresponding acids to

334 the individual enantiomers of ethyl 4-methyloctanoate did not significantly affect catches. As in

335 the first experiment, catches in traps baited with ethyl $(S)$-4-methyloctanoate and the

336 combination with the corresponding acid were significantly lower than those in traps baited with

337 the racemic or $(R)$ - equivalents. Increasing the release rate of racemic ethyl 4-methyl alone by

338 using a polyethylene sachet rather than the polyethylene vial increased catches to a level not

339 significantly different from catches in traps baited with the ChemTica lure (release rates under

340 laboratory conditions $1.0 \mathrm{mg} / \mathrm{d}, 20.0 \mathrm{mg} / \mathrm{d}$ and $9.1 \mathrm{mg} / \mathrm{d}$, respectively; Table 1).

\section{Discussion}

\section{Pheromone Components}

344 The results described here indicate that ethyl 4-methyloctanoate is a component of the male-

345 produced aggregation pheromone of the new haplotype Guam strain of O. rhinoceros (CRB-G),

346 causing a strong EAG response from antennae of both male and female beetles and being

347 attractive to both male and female beetles in field trapping tests. As such it may serve as a sex-

348 aggregation pheromone (Cardé 2014), but this was not investigated further. The male beetles

349 also produce 4-methyloctanoic acid in very variable amounts relative to the ethyl ester and

350 sometimes the acid was produced with none of the ester detectable. The acid did not elicit an

351 EAG response from male or female beetles. In field trapping tests, catches in traps baited with

352 the acid were low, although significantly greater than those in unbaited traps which trapped no

353 beetles, possibly due to the relatively restricted trap entrance. In most cases, addition of the acid 
354 to the ester did not affect catches, and only in one case it did significantly increase catches, so it

355 seems unlikely that 4-methyloctanoic acid is an essential component of the aggregation

356 pheromone. Similar results were reported previously for the standard strain of $O$. rhinoceros

357 (CRB) by both Hallett et al. (1995) and Morin et al. (1996).

Ethyl 4-methyloctanoate is produced by males of all the other species of Oryctes reported to date: O. agamemnon (Said et al. 2015), O. elegans (Rochat et al. 2004), and O. monoceros

360 (Allou et al. 2006; Gries et al. 1994) and attractive to both female and male conspsecifics. In all

361 species investigated, the corresponding acid was also reported to be produced, and in O. elegans

362 it was the predominant component and more attractive to conspecifics than the ethyl ester,

363 particularly when combined with date palm volatiles (Rochat et al. 2004). Methyl 4-

364 methyloctanoate was reported in volatiles collected from O. elegans (Rochat et al. 2004), as were

365 4-methyloctan-1-ol and the corresponding acetate in volatiles from O. agamemnon (Said et al.

366 2015) and O. elegans (Rochat et al. 2004), but no behavioral function was found for these

367 compounds. We could not detect the latter three compounds in volatiles from males of CRB-G or

368 CRB-S. In EAG studies, the antennae of both male and female CRB-G gave strong and 369 consistent responses to ethyl 4-methyloctanoate, occasional weak responses to methyl 4370 methyloctanoate and no responses to 4-methyloctan-1-ol and the corresponding acetate.

Significant amounts of $(E)$-geranic acid were detected at one stage in collections from

372 both male and female CRB-G beetles on sugarcane. It was thought this might have come from

373 the sugarcane, but it was not possible to test this as that batch of sugarcane had been used up.

374 Traps baited with $(E)$-geranic acid caught very low numbers of CRB-G beetles, although

375 significantly more than the zero catches in unbaited traps.

\section{Stereochemistry}

377 The stereochemistries of the ethyl 4-methyloctanoate and 4-methyloctanoic acid produced by 378 male CRB-G were determined by analysis on a commercially available $\beta$-cyclodextrin GC 379 column. This gave baseline separation of the enantiomers of the acid, but no detectable 380 separation of the enantiomers of the ester. However, the ester could easily be hydrolyzed to the 381 corresponding acid on sub-microgram scale and its stereochemistry determined. Separation of 382 the enantiomers of various 2-, 3- and 4-methylbranched acids by GC analysis on a modified $\gamma$ - 
cyclodextrin phase was reported by Karl et al. (1994b). Heinsman et al. (1998; 2001) described

384 separation of enantiomers of both 4-methyloctanoic acid and the corresponding ethyl and butyl

385 esters on $\beta$-cyclodextrin phases. It is not known why we obtained no detectable separation of the 386 esters on a similar phase; the only obvious difference is that we used helium as carrier gas while 387 Heinsman et al. $(1998,2001)$ used hydrogen. produced by male CRB-G beetles were determined to be exclusively the $(R)$-enantiomers. This was in contrast to the suggestion by Hallett et al. (1995) that CRB-S beetles from Indonesia produced the $(S)$-enantiomers, based on significantly higher catches of CRB-S in traps baited with the $(S)$-enantiomer than in those baited with the $(R)$-enantiomer. However, our analyses of 393 the ethyl 4-methyloctanoate and 4-methyloctanoic acid produced by CRB-S from Papua New 394 Guinea showed that these were both the $(R)$-enantiomers, identical to those produced by CRB-G. 395 Moreover, in our field trapping tests, traps baited with ethyl $(R)$-4-methyloctanoate caught more 396 CRB-G than those baited with the (S)-enantiomer. Francke and Akasaka (pers comm 2018) also 397 found CRB produced the $(R)$-enantiomer of ethyl 4-methyloctanoate by HPLC analysis of the 398 fluorescent $(S)$ - and $(R)$-1-(anthracene-2,3-dicarboximido)-2-propyl derivatives of the 399 corresponding acid (cf. Mori et al. 2016).

The reasons for the misleading result of Hallet et al. (1995) can only be speculated after over 25 years. The enantiomers of ethyl 4-methyloctanoate used by Hallett et al. (1995) were 402 synthesized from enantiomers of citronellol. ( $S$ )-Citronellol (97.5\% ee) gave ethyl $(R)$-4403 methyloctanoate and $(R)$-citronellol (96\% ee) gave the $(S)$-enantiomer. The stereochemistries of 404 the enantiomers of ethyl 4-methyloctanoate produced could not be determined directly and it was 405 assumed that these had the same stereochemistries as those of the corresponding starting 406 materials, i.e. similar to those tested in our work. However, catches in the trapping experiment 407 by Hallet et al. (1995) were low (means $\leq 7$ beetles per trap over two weeks) and differences not 408 great, even though statistically significant.

\section{Synthesis}

410 The enantiomers of 4-methyloctanoic acid have previously been prepared by multistep syntheses 411 from the enantiomers of citronellol (Hallett et al. 1995) or citronellal (Mori et al. 2016) which are 
412 both commercially-available in high enantiomeric purities. Karl et al. (1994a) synthesized

413 enantiomers of 2-methyl acids by chromatographic separation of the diastereoisomeric

414 phenylglycinol amides followed by chain elongation to give both 3- and 4-methyl acids. Muñoz

415 et al. (2009) used $(R, R)$ - and $(S, S)$-pseudoephedrine-propionamides as chiral auxiliaries.

416 Stereospecific alkylation with a protected 3-iodo-1-propanol was followed by removal of the 417 auxiliary by hydrolysis, chain extension and oxidation.

In our work, the enantiomers of 4-methyloctanoic acid and the corresponding ethyl ester were conveniently resolved enzymatically in multigram quantities as reference standards and for field testing. Heinsman et al. $(1998 ; 2001)$ reported that immobilized lipase from Candida antarctica acts selectively on the $(R)$-enantiomer, so that the acid can be selectively esterified in 422 ethanol or the ethyl ester can be selectively hydrolyzed in aqueous buffer. Moreover, the acid 423 could be separated from the ester by extraction with aqueous base and subsequent acidification 424 without resort to chromatography. The stereoselectivity of this lipase for the enantiomers of 4methyloctanoic acid was not as high as for 2-alkanols and the corresponding acetates (Hall et al. 2012), but two cycles produced material with at least $94 \%$ ee.

\section{Pheromone Production}

428 In our hands, beetles of both CRB-G and CRB-S strains did not start producing pheromone for 429 several months after emergence and arrival at NRI. In attempts to induce pheromone production, 430 various substrates including palm detritus, soil and paper were tried, as were various foodstuffs 431 including banana, apple, palm hearts and sugarcane, without any obvious effects. Beetles were 432 kept under laboratory conditions and did not fly, so whether this pattern is replicated in the field 433 is unknown. This has not been reported for other Oryctes species, although Prof Didier Rochat 434 did suggest that pheromone production can be very variable and erratic (pers comm 2018).

\section{Practical Aspects}

436 Ethyl 4-methyloctanoate is highly attractive to both CRB-G and CRB-S strains of O. rhinoceros. 437 Although male beetles produce the $(R)$-enantiomer, the racemic material is just as attractive as 438 this enantiomer in field tests. The $(S)$-enantiomer is significantly less attractive, although it is not 439 possible to say whether the $(S)$-enantiomer is attractive at all as the material used in our field 440 tests contained small amounts of the $(R)$-enantiomer. Catches of CRB-G beetles with racemic 
441 ethyl 4-methyloctanoate released at $1 \mathrm{mg} / \mathrm{d}$ were generally less than those with the standard

442 ChemTica lure releasing at $9.1 \mathrm{mg} / \mathrm{d}$ under laboratory conditions, although not significantly so in

443 the first field trapping experiment. Increasing the release rate to $20.0 \mathrm{mg} / \mathrm{d}$ significantly

444 increased catches relative to catches with a release rate of $1 \mathrm{mg} / \mathrm{d}$ in the second experiment,

445 although not significantly more than catches with the standard dispenser at $9.1 \mathrm{mg} / \mathrm{d}$.

446 As indicated above, catches of CRB-G in traps baited with racemic 4-methyloctanoic 447 acid or the individual enantiomers were low. Addition of the racemic acid at $1.4 \mathrm{mg} / \mathrm{d}$ to 448 racemic ethyl 4-methyloctanoate at $1.0 \mathrm{mg} / \mathrm{d}$ significantly increased catches in the second 449 experiment, although addition of the individual enantiomers of the acid to the corresponding 450 ethyl ester had no significant effect in either case. Thus, although $(R)$-4-methyloctanoic acid is 451 probably not an essential component of the naturally-produced aggregation pheromone which 452 seems to consist of the single component, ethyl $(R)$-4-methyloctanoate, it may be possible to 453 increase the attractiveness of the more readily available racemic ester by addition of the racemic 454 acid. Depending upon the costs of production of the compounds and the manufacture of two 455 separate lures, it may be economically advantageous to add the racemic acid released at $1.4 \mathrm{mg} / \mathrm{d}$ 456 to the racemic ethyl 4-methyloctanoate released at $1 \mathrm{mg} / \mathrm{d}$ rather than using one lure releasing 457 racemic ethyl 4-methyloctanoate at $9.1 \mathrm{mg} / \mathrm{d}$.

\section{Acknowledgements}

460 The authors are grateful to the Papua New Guinea Oil Palm Research Association for partially 461 funding this work; the previous Director, Dr Luc Bonneau, approved the funding support whilst 462 the current Director, Mr Cheah See Siang, and Director of Research, Dr Katayo Sagata, 463 supported the publication of this paper. The General Manager for Guadalcal Plains Oil Palm 464 Ltd, Mr Craig Gibsone, is acknowledged for logistics support for the field evaluation study, and 465 the Technical Services Division (TSD) team supported with the field activities. We also thank 466 Prof Angel Guerrero, Barcelona, Spain, for providing an authentic sample of 4-methyloctanoic 467 enriched in the $(R)$-enantiomer, and Charles Dewhurst for initiating the collaboration and 468 encouraging us throughout this work. 
471 Allou K, Morin J-P, Kouassi P, N'klo FH, Rochat D (2006). Oryctes monoceros trapping with 472 synthetic pheromone and palm material in Ivory Coast. J Chem Ecol 32:1743-1754

473 Bedford GO (2013a) Biology and management of palm dynastid beetles: recent advances. Annu 474 Rev Entomol 58:353-372

475 Bedford GO (2013b) Long-term reduction in damage by rhinoceros beetle Oryctes rhinoceros 476 (L.) (Coleoptera: Scarabaeidae: Dynastinae) to coconut palms at Oryctes nudivirus release sites 477 on Viti Levu, Fiji. Afr J Agr Res 8:6422-6425

478 Cardé RT (2014) Defining attraction and aggregation pheromones: teleological versus functional 479 perspectives. J Chem Ecol 40:519-520

480 Catley A (1969) The coconut rhinoceros beetle Oryctes rhinoceros (L)

481 (Coleoptera:Scarabaeidae: Dynastinae). Pest Articles News Summ 15:18-30

482 Gries G, Gries R, Perez AL, Oehlschlager AC, Gonzales LM, Pierce HD, Zebeyou M, Kouame 483 B (1994) Aggregation pheromone of the African rhinoceros beetle, Oryctes monoceros (Olivier) 484 (Coleoptera: Scarabaeidae). Z Naturforsch C 49:363-366

485 Hall DR, Amarawardana L, Cross JV, Francke W, Boddum T, Hilbur Y (2012) The chemical 486 ecology of cecidomyiid midges (Diptera: Cecidomyiidae). J Chem Ecol 38:2-22

487 Hallett RH, Perez AL, Gries G, Gries R, Pierce, HD, Yue J, Oehlschlager AC, Gonzalez LM, 488 Borden JH (1995) Aggregation pheromone of coconut rhinoceros beetle, Oryctes rhinoceros (L.) 489 (Coleoptera: Scarabaeidae). J Chem Ecol 21:1549-1570

490 Heinsman NWJT, Orrenius SC, Marcelis CLM, de Sousa Teixeira A, Franssen MCR, van der 491 Padt A, Jongejan JA, de Groot A (1998) Lipase mediated resolution of $\gamma$-branched chain fatty 492 acid methyl esters. Biocatal Biotransfor 16:145-162

493 Heinsman NWJT, Valente AM, Smienk HGF, van der Padt A, Franssen MCR, de Groot A, van't 494 Riet K (2001) The effect of ethanol on the kinetics of lipase-mediated enantioselective 
495 esterification of 4-methyloctanoic acid and the hydrolysis of its ethyl ester, Biotechnol Bioeng 496 76:193-199

497 Huger AM (2005) The Oryctes virus: its detection, identification, and implementation in 498 biological control of the coconut palm rhinoceros beetle, Oryctes rhinoceros (Coleoptera: 499 Scarabaeidae). J Invertebr Pathol 89:78-84

500 Jackson TA (2009) The use of Oryctes virus for control of rhinoceros beetle in the Pacific 501 Islands. In: Hajek AE, Glare T, O’Callaghan M (Eds.), Use of Microbes for Control and 502 Eradication of Invasive Arthropods. Springer, Dordrecht, The Netherlands, pp.113-140

503 Karl V, Kaunzinger A, Gutser J, Steuer P, Angles-Angel J, Mosandl A (1994a) Stereoisomeric 504 flavour compounds LXVII. 2-, 3-, and 4-alkyl-branched acids, Part 1: general approach to the 505 synthesis of the enantiopure acids. Chirality 6:420-426

506 Karl V, Gutser J, Dietrich A, Maas B, Mosandl A (1994b) Stereoisomeric flavour compounds 507 LXVIII. 2-, 3-, and 4-alkyl-branched acids, Part 2: chirospecific analysis and sensory evaluation. 508 Chirality 6:427-434

509 Marshall SDG, Moore A, Vaqalo M, Noble A, Jackson TA (2017) A new haplotype of the 510 coconut rhinoceros beetle, Oryctes rhinoceros, has escaped biological control by Oryctes

511 rhinoceros nudivirus and is invading Pacific Islands. J Invertebr Path 149:127-134

512 Mini A, Prabhu VKK (1988) Sexual dimorphism in the larva and pupa of coconut rhinoceros 513 beetle Oryctes rhinoceros (Coleoptera: Scarabaeidae). Curr Sci 57:686-687

514 Moore A, Jackson T, Roland Q, Bassler P, Campbell R (2015) Coconut rhinoceros beetles 515 (Coleoptera: Scarabaeidae) develop in arboreal breeding sites in Guam. Fla Entomol 98:10125161014

517 Mori K, Akasaka K (2016) Pheromone synthesis. Part 258. Synthesis of the enantiomers of the 518 beetle pheromones ethyl 4-methylheptanoate, 4-methyloctanoic acid and 4-methyl-1-nonanol, 519 and HPLC analysis of their derivatives to determine their enantiomeric purities. Tetrahedron520 Asymmetr 27:182-187 
521 Morin JP, Rochat D, Malosse C, Lettere M, De Chenon RD, Wibwo H, Descoins C (1996) Ethyl 522 4-methyloctanoate, major component of Oryctes rhinoceros (L.) (Coleoptera, Dynastidae) male 523 pheromone. CR Acad Sci Paris 319:595-602

524 Muñoz L, Bosch MP, Rosell G, Guerrero A (2009) Asymmetric synthesis of $(R)$ - and $(S)$-4525 methyloctanoic acids. A new route to chiral fatty acids with remote stereocenters. Tetrahedron526 Asymmetr 20:420-424

527 Renou M, Tauban D, Morin J-P (1998) Structure and function of antennal pore plate sensilla of 528 Oryctes rhinoceros (L.) (Coleoptera: Dynastidae). J Insect Morphol Embryol 16:116-122

529 Rochat D, Mohammadpoor K, Malosse Ch, Avand-Faghih A, Lettere M, Beauhaire J, Morin J.530 P, Pezier A, Renou M, Abdollahi GA (2004). Male aggregation pheromone of date palm fruit 531 stalk borer Oryctes elegans. J Chem Ecol 30:387-407

532 Said I, Hasni N, Abdallah Z, Couzi P, Ouhichi M, Renou M, Rochat D (2015) Identification of 533 the aggregation pheromone of the date palm root borer Oryctes agamemnon. J Chem Ecol $534 \quad 41: 446-457$

535 Secretariat of the Pacific Community (2015) An emerging biotype of Coconut Rhinoceros Beetle 536 discovered in the Pacific. Pest Alert 51 
538 Table 1 Release rates of ethyl 4-methyloctanoate, 4-methyloctanoic acid and geranic acid from 539 dispensers measured under laboratory conditions by weight loss $\left(N=2 ; 20-22{ }^{\circ} \mathrm{C}\right.$; for data see 540 Supplementary Material Figs S3-S6).

\begin{tabular}{|c|c|c|c|c|c|}
\hline \multirow[b]{3}{*}{ Compound } & \multicolumn{5}{|c|}{ Mean release rate $(\mathrm{mg} / \mathrm{d})$} \\
\hline & \multirow[b]{2}{*}{$\begin{array}{l}\text { Polyethylene } \\
\text { vial }\end{array}$} & \multicolumn{3}{|c|}{ Polyethylene sachet } & \multirow[b]{2}{*}{$\begin{array}{l}\text { Standard } \\
\text { ChemTica }\end{array}$} \\
\hline & & $\begin{array}{l}5 \mathrm{~cm} \times 5 \mathrm{~cm} \times \\
60 \mu\end{array}$ & $\begin{array}{l}5 \mathrm{~cm} \times 5 \\
\mathrm{~cm} \times 120 \mu\end{array}$ & $\begin{array}{l}2.5 \mathrm{~cm} \times 5 \\
\mathrm{~cm} \times 250 \mu\end{array}$ & \\
\hline $\begin{array}{l}\text { Ethyl 4- } \\
\text { methyloctanoate }\end{array}$ & 1.0 & & & 20.0 & 9.1 \\
\hline $\begin{array}{l}\text { 4-Methyloctanoic } \\
\text { acid }\end{array}$ & & 1.5 & 1.4 & 1.2 & \\
\hline Geranic acid & & 0.6 & 0.3 & & \\
\hline
\end{tabular}

541

542 
543 Table 2 Dispensers and loadings of lures used in two field trapping experiments

\section{Dispenser/Amount}

\begin{tabular}{|c|c|c|c|c|}
\hline \multirow[b]{2}{*}{ Compound } & \multicolumn{4}{|c|}{ Polyethylene sachet } \\
\hline & $\begin{array}{l}\text { Polyethylene } \\
\text { vial }\end{array}$ & $\begin{array}{l}5 \mathrm{~cm} \times 5 \mathrm{~cm} \\
\times 60 \mu\end{array}$ & $\begin{array}{l}5 \mathrm{~cm} \times 5 \mathrm{~cm} \\
\times 120 \mu\end{array}$ & $\begin{array}{l}2.5 \mathrm{~cm} \times 5 \\
\mathrm{~cm} \times 250 \mu\end{array}$ \\
\hline \multicolumn{5}{|l|}{ Experiment 1} \\
\hline Ethyl 4-methyloctanoate & $100 \mu 1$ & & & \\
\hline Ethyl $(S)$-4-methyloctanoate & $100 \mu 1$ & & & \\
\hline Ethyl $(R)$-4-methyloctanoate & $100 \mu 1$ & & & \\
\hline 4-Methyloctanoic acid & & & $100 \mu 1$ & \\
\hline$(S)$-4-Methyloctanoic acid & & & $100 \mu 1$ & \\
\hline (R) 4-Methyloctanoic acid & & & $100 \mu 1$ & \\
\hline Geranic acid & & $100 \mu 1$ & & \\
\hline \multicolumn{5}{|l|}{ Experiment 2} \\
\hline Ethyl 4-methyloctanoate & $100 \mu 1$ & & & \\
\hline Ethyl $(S)$-4-methyloctanoate & $100 \mu \mathrm{l}$ & & & \\
\hline Ethyl $(R)$-4-methyloctanoate & $100 \mu 1$ & & & \\
\hline Ethyl 4-methyloctanoate & $100 \mu 1$ & & & \\
\hline + 4-methyloctanoic acid & & & & $100 \mu \mathrm{l}$ \\
\hline Ethyl $(S)$-4-methyloctanoate + & $100 \mu 1$ & & & \\
\hline$(S)$-4-methyloctanoic acid & & & & $100 \mu 1$ \\
\hline Ethyl $(R)$-4-methyloctanoate + & $100 \mu 1$ & & & \\
\hline$(R)$-4-methyloctanoic acid & & & & $100 \mu 1$ \\
\hline Ethyl 4-methyloctanoate & & & & $500 \mu 1$ \\
\hline
\end{tabular}

544

545

546 


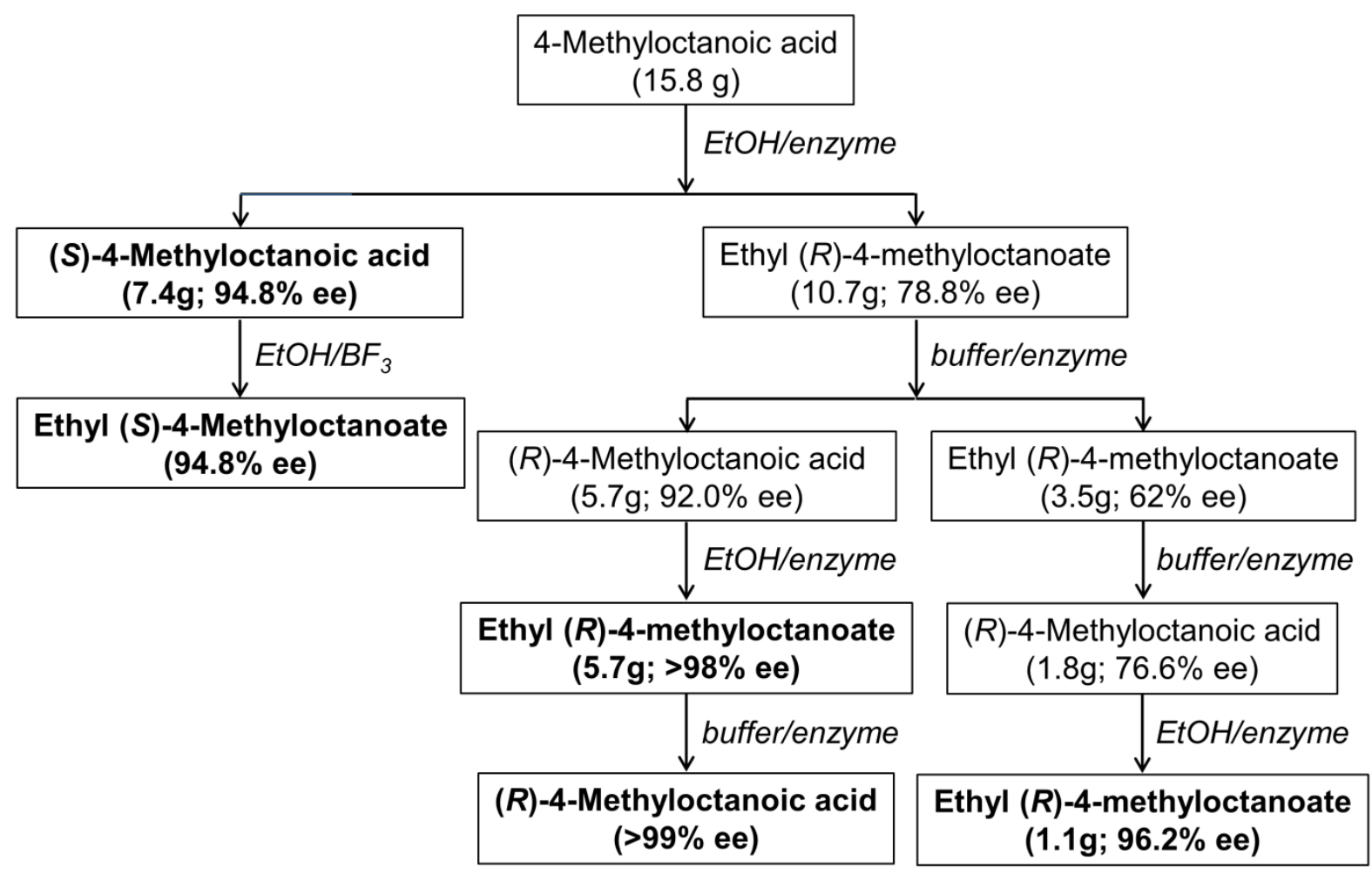

548 Fig. 1 Enzymatic resolution of racemic 4-methyloctanoic acid (enzyme: immobilized lipase

549 from Candida antarctica; buffer: aqueous $1 \mathrm{M} \mathrm{K}_{2} \mathrm{HPO}_{4}$; samples in bold were used in field

550 trapping experiments) 


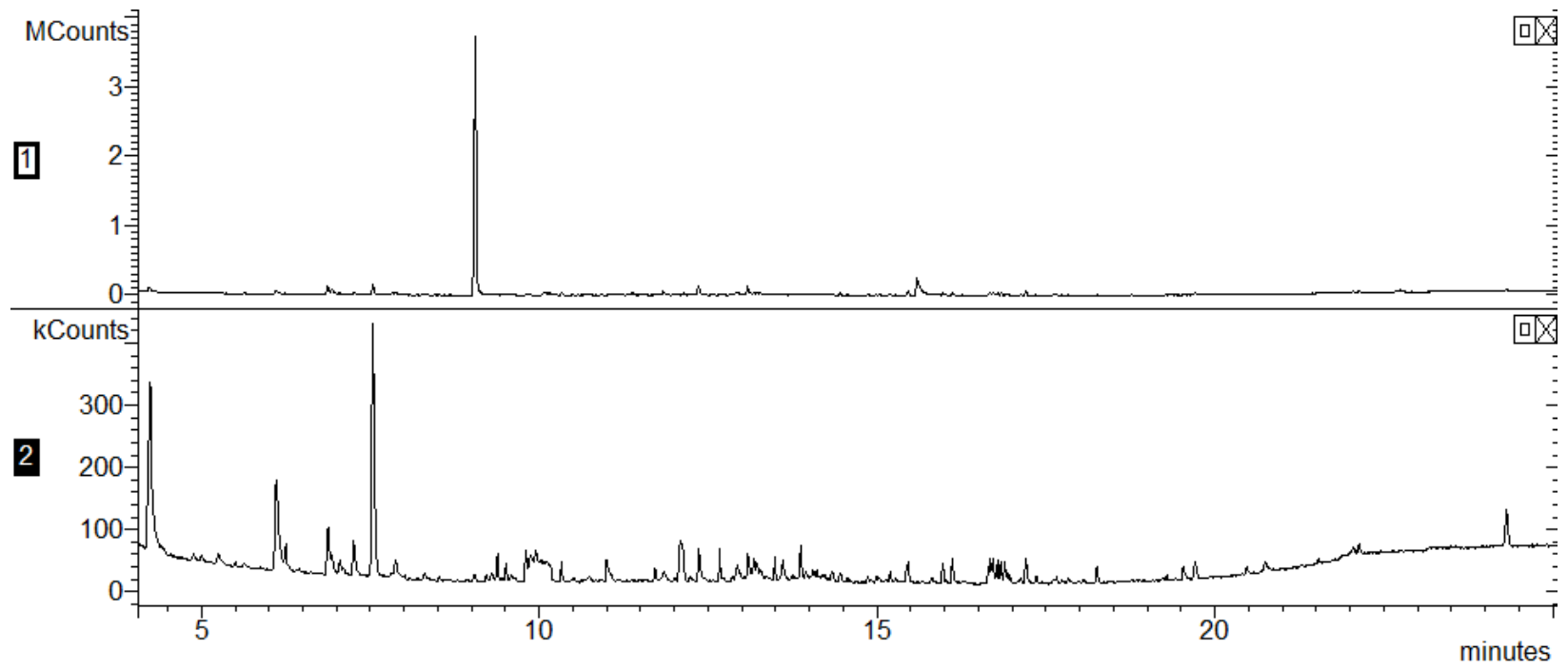

553 Fig. 2 GC-MS analyses of volatiles collected from five male Guam strain Oryctes rhinoceros

554 (CRB-G) (upper) and seven female CRB-G (lower); ethyl 4-methyloctanoate at $9.06 \mathrm{~min}, 4-$ 555 methyloctanoic acid at $15.60 \mathrm{~min}$. 


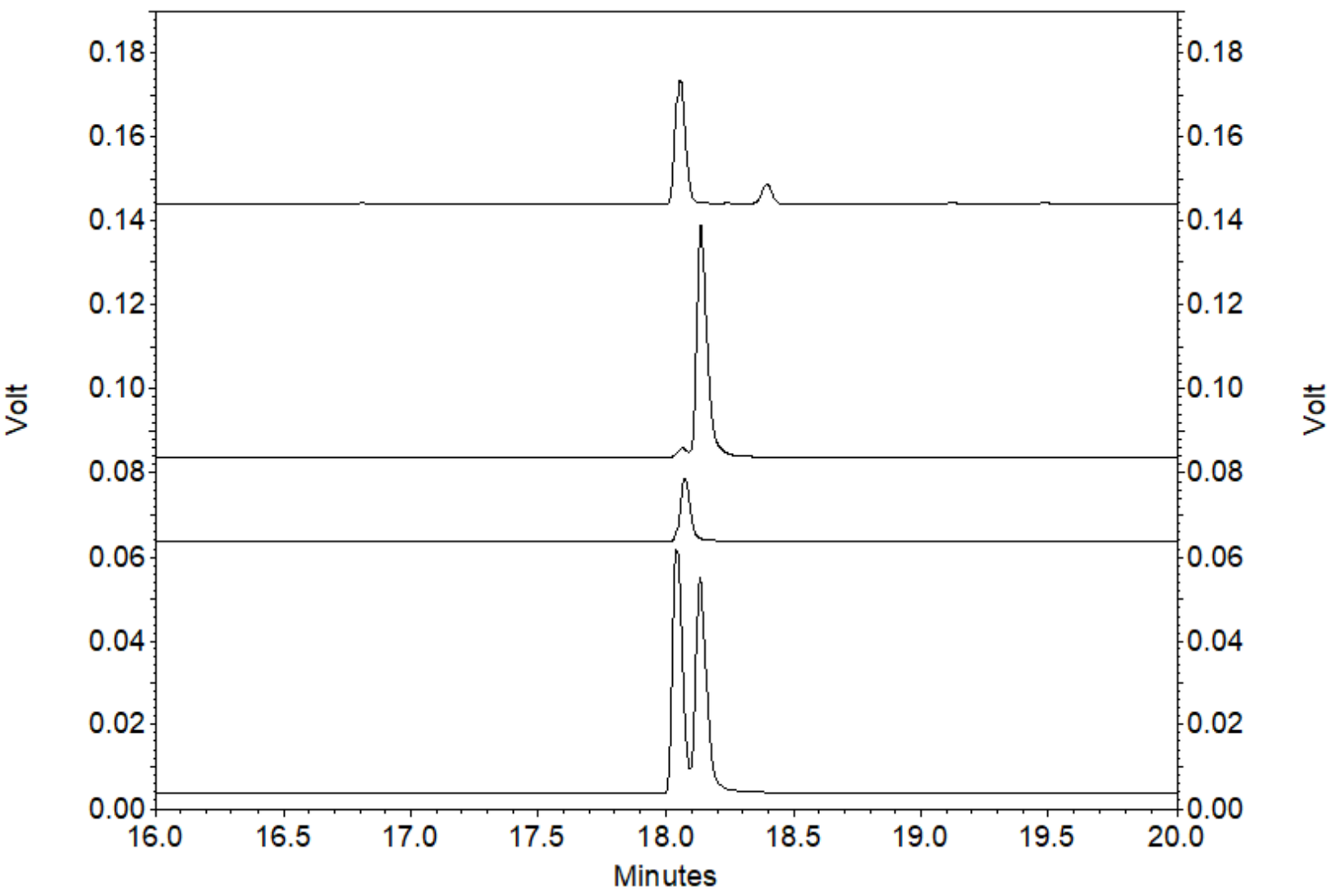

558 Fig. 3 Analyses on enantiospecific cyclodextrin GC column of synthetic standards of (from

559 bottom) racemic, $(R)$ - and $(S)$-4-methyloctanoic acids and a volatile collection from male Guam

560 strain Oryctes rhinoceros beetles (CRB-G) after hydrolysis of the ethyl 4-methyloctanoate,

561 showing this is exclusively the $(R)$-enantiomer 


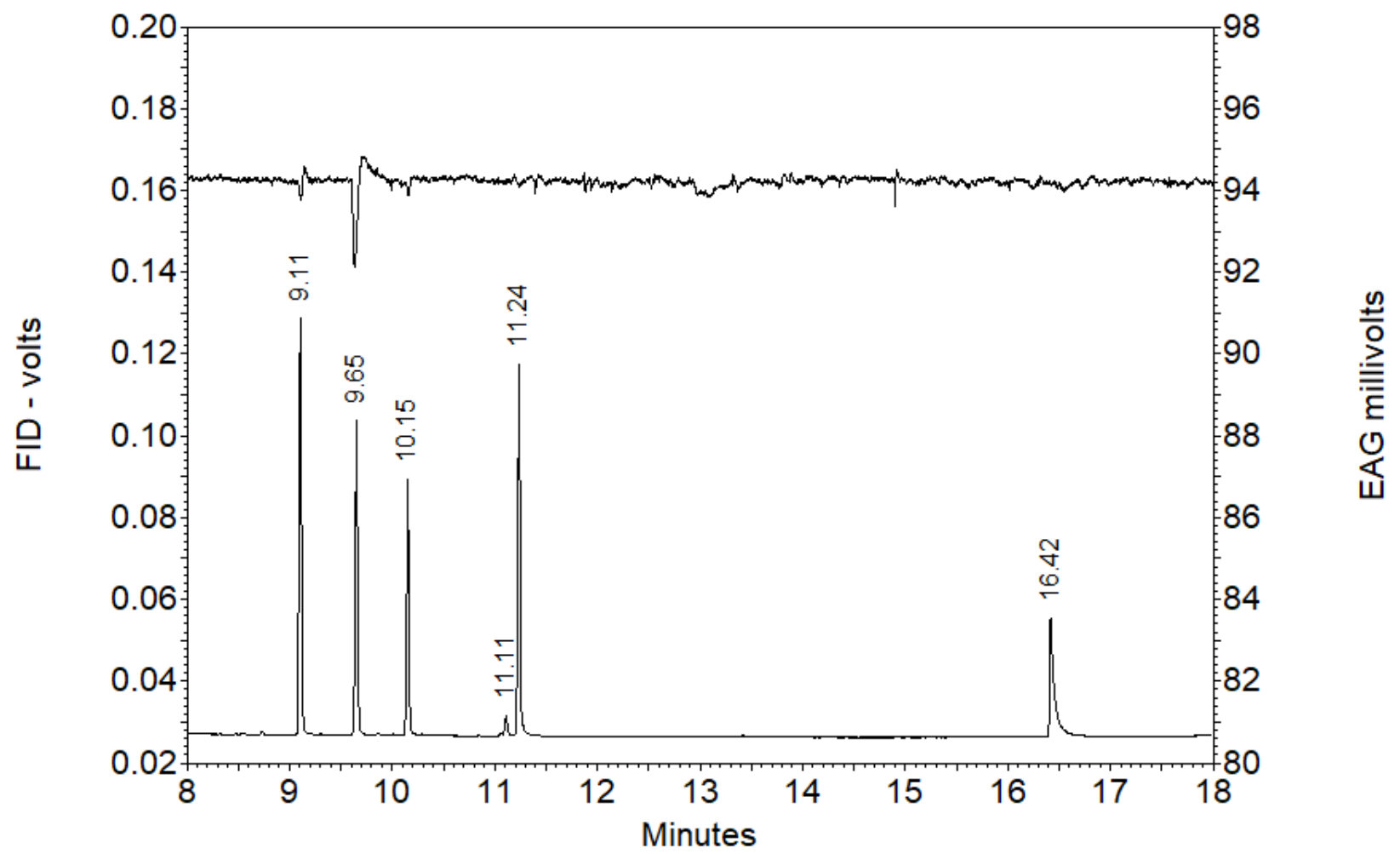

564 Fig. 4 GC-EAG Analysis of synthetic standards with antenna of male Guam strain Oryctes

565 rhinoceros (CRB-G). Upper trace EAG, lower trace FID; compounds in order of elution: methyl

566 4-methyloctanoate, ethyl 4-methyloctanoate, 4-methyl-1-octyl acetate, 4-methyl-1-octanol, 4-

567 methyloctanoic acid 


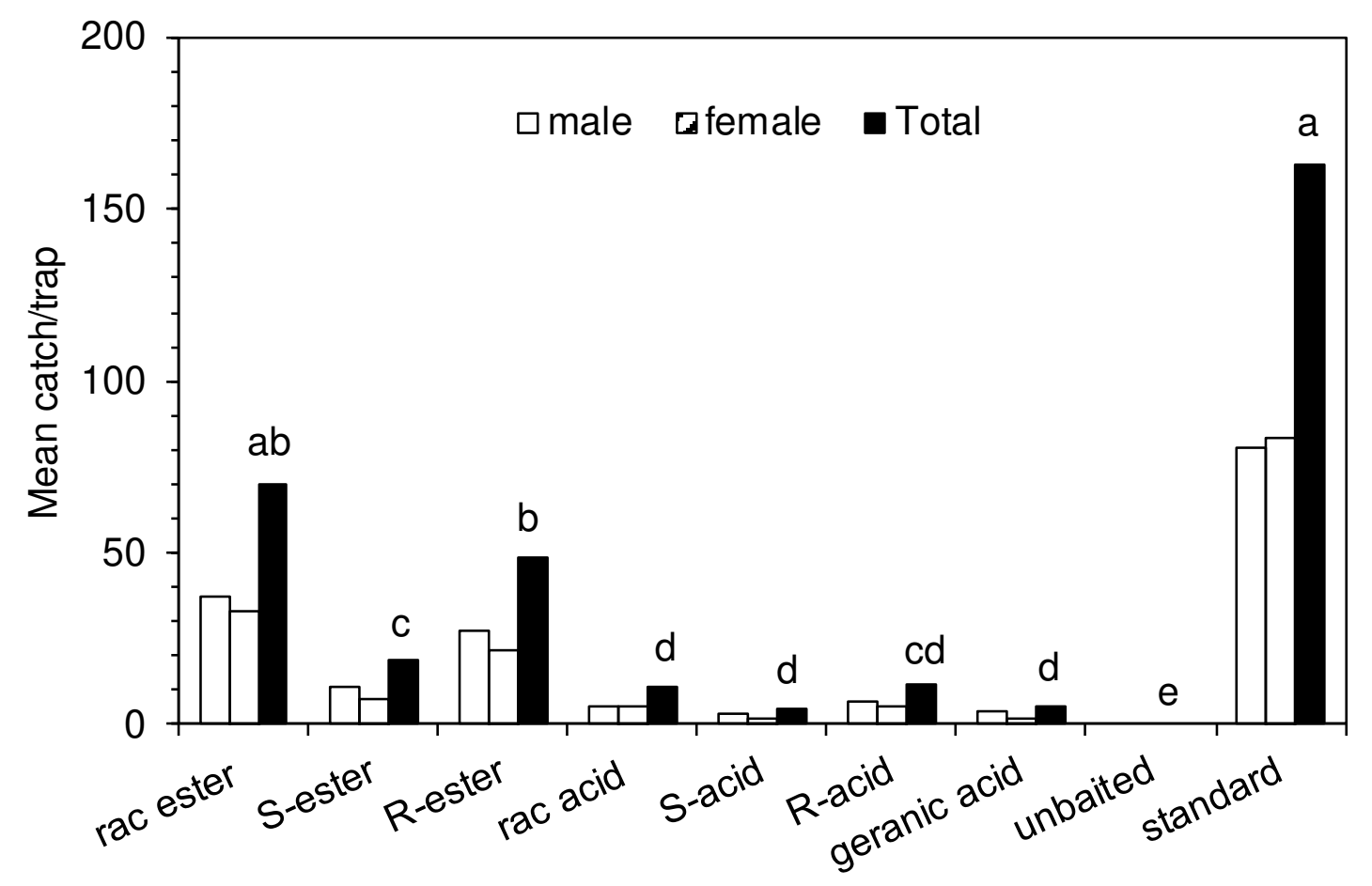

569

570 Fig. 5 Mean catches of Guam strain Oryctes rhinoceros (CRB-G) beetles in traps baited with

571 individual chemicals in Experiment 1 (8 May - 6 June 2017; $N=6$ ). Means with different letters

572 are significantly different $(P<0.05)$ after analysis of variance on total catches transformed to

$573 \log (\mathrm{x}+1)$ and LSD test of significance of differences between means $(F=25.26 ; \mathrm{df}=7,35 ; P<$

574 0.001). Ester is ethyl 4-methyloctanoate; acid is 4-methyloctanoic acid; geranic acid is $(E)$ -

575 geranic acid; standard is Sime Darby/ChemTica lure 


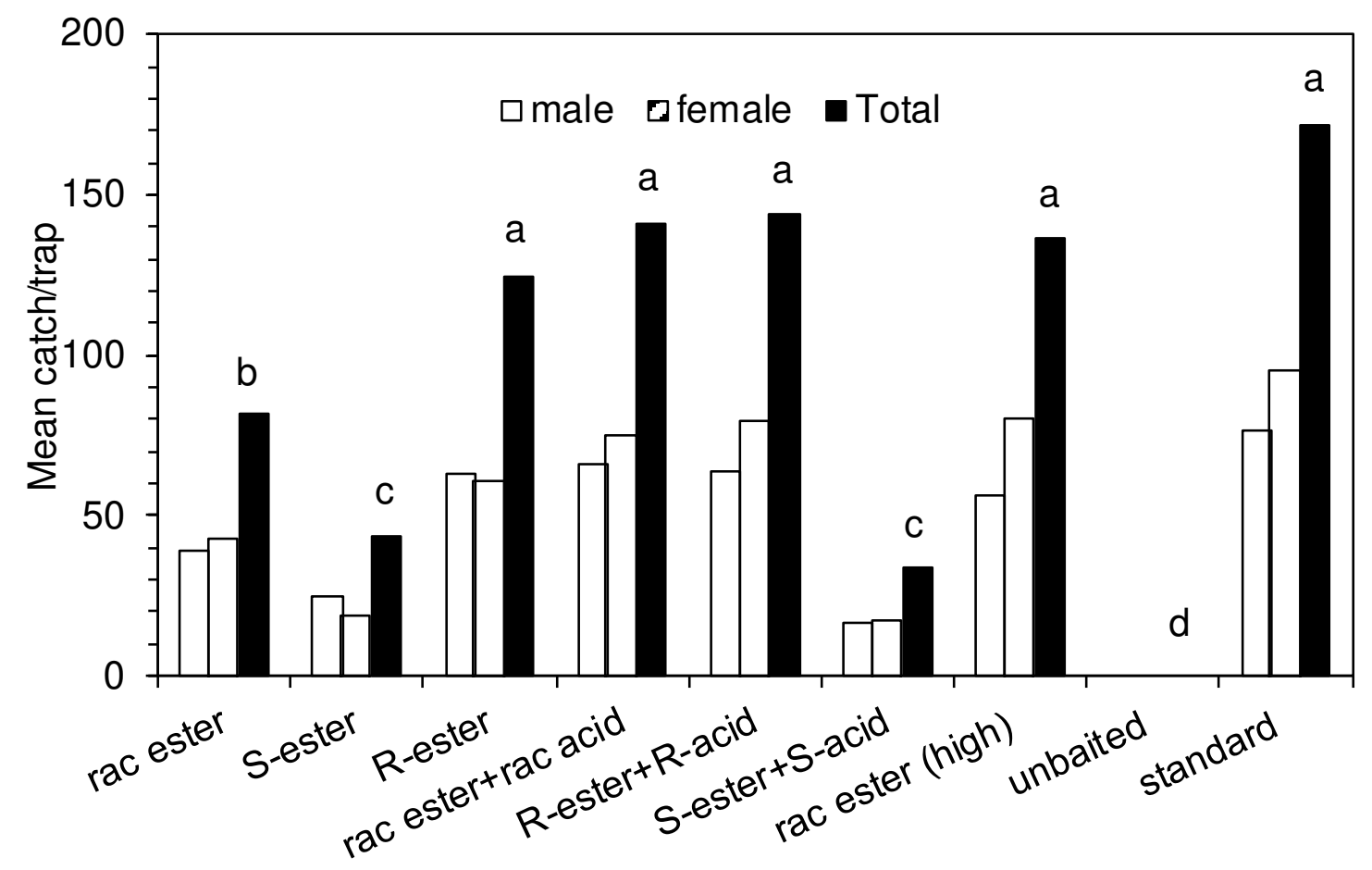

578 Fig. 6 Mean catches of Guam strain Oryctes rhinoceros (CRB-G) beetles in traps baited with 579 individual chemicals in Experiment 2 (20 June - 11 July 2017; $N=6$ ). Means with different 580 letters are significantly different $(P<0.05)$ after analysis of variance on total catches 581 transformed to $\log (\mathrm{x}+1)$ and LSD test of significance of differences between means $(F=14.96$;

$582 \mathrm{df}=7,35 ; P<0.001)$. Ester is ethyl 4-methyloctanoate; acid is 4-methyloctanoic acid; standard is 583 Sime Darby/ChemTica lure 


\section{Supplementary Files}

This is a list of supplementary files associated with this preprint. Click to download.

- HallSupplementaryMaterial.docx 